REVISTA ECONOMÍA

Vol. 68, N. ${ }^{\circ}$ I08 (noviembre 2016), 75-95

\title{
LA DOLARIZACIÓN MÁS ALLÁ DE LA ESTABILIDAD MONETARIA
}

\author{
PABLO LUCIO PAREDES \\ Universidad San Francisco de Quito
}

Recepción manuscrito: 23 de septiembre de 2016

Aceptación versión final: 31 de octubre de 2016

\begin{abstract}
RESUMEN En este artículo se analizan, de manera general, algunos de los temas ligados al proceso de decisión y avance de la dolarización formal que el Ecuador inició en enero del 2000, lo cual inevitablemente nos lleva a las alternativas existentes a este sistema, en esa época así como hoy en día. Y de la misma manera se invita a una reflexión sobre el rol que el dinero cumple en la economía y la manera cómo en el mundo - y naturalmente en Ecuador- ello ha generado distorsiones importantes en el manejo económico y, a partir de allí, —en un proceso de ida y vuelta - en los sistemas políticos y sociales.
\end{abstract}

PALABRAS CLAVE Dolarización, sistemas monetarios en el mundo, historia monetaria ecuatoriana, estabilidad monetaria.

\begin{abstract}
In this article we analyze, in a general way, some of the topics related to the decision and advancement process of formal dollarization that started in Ecuador in January, 2000, which inevitably takes us to alternatives that are present in this system back then and today. Likewise, we invite to reflect on the role that money plays in the economy, and the way how, in the world -and naturally in Ecuador - that has generated significant distortions in the economic management, and from that point — in a complete round process - in the social and political systems.

KEYWORDS Dollarization, monetary systems in the world, Ecuadorian monetary history, monetary stability.

JEL CODES E42, E58, O24.
\end{abstract}

\section{INTRODUCCIÓN}

Como la dolarización es esencialmente un sistema que quita a los grupos políticos y de intereses específicos el manejo del dinero, es esencial evaluar lo que hoy sucede en el mundo incluso en países donde ese manejo es institucionalmente independiente. El mundo tiene una extraña historia monetaria que se puede resumir así: todas las experiencias muestran que la manipulación del dinero - como resultado de presiones políticas, sociales y económicas-, entendida de manera sencilla como la creación excesiva de dinero para resolver problemas reales, conduce inevitablemente a tensiones inflacionarias y distorsiones en las decisiones de los agentes económicos, cuyos resultados son peores que los que se quería inicialmente corregir, 
y casi inevitablemente se cae en círculos viciosos que requieren de mayor manipulación monetaria que ahonda aún más los problemas.

Cabe recordar esto porque la historia ha repetido mil veces esta misma polémica y es hoy la misma discusión que se ha planteado antes y después de la crisis del 2008. Por un lado, están los que consideran que la crisis no fue el resultado de desajustes monetarios y/o fiscales - canalizados vía monetaria, porque esencialmente se trata de los bancos centrales comprando papeles estatales, o manejándose vía una baja artificial de las tasas de interés-, sino de los abusos de la estructura bancaria y capitalista moderna, y que, por ende, la solución consiste más bien en más empuje fiscal y monetario; incluso ante la pobre reacción de las economías a estos estímulos, reclaman que haya más de lo mismo, o se ilusionan con que la economía sí está mejor gracias a estos estímulos, y que políticas contrarias solo hubieran llevado a crisis más profundas. Por otro lado, están los que consideran que la crisis es el estallido de una burbuja creada por los excesos monetarios y fiscales - que distorsionan las decisiones de consumo e inversión-, y que, por tanto, el único camino sensato es permitir que la economía recupere a nivel microeconómico y sectorial sus equilibrios fundamentales de precios — salarios, tasas de interés, precios de activos, etc.-, los cuales devolverán una senda de sanas decisiones personales y empresariales en el campo de la inversión, consumo, empleo; y que mientras se mantengan los programas de estímulo monetario/fiscal, el único resultado será retrasar o, peor aún, impedir el necesario ajuste y la recuperación de la economía real.

\section{EL CASO DE ROMA}

El primer ejemplo que viene a la memoria es el de los emperadores romanos en los siglos posteriores a la era común que, sometidos a una intensa presión social para resolver problemas de diversa orden - que ya no eran tan fáciles de resolver por el retroceso del poderío romano y la fácil captación de rentas guerreras en otros territorios más los cambios demográficos-, decidieron como mecanismo alterno a la productividad, priorización de gastos o impuestos, simplemente mantener el valor nominal de las monedas, pero quitándoles una parte de su respaldo en metálico. Resultado inicial: auge en la actividad económica. Resultado segundo: incremento del nivel de precios y de la inflación que llevaban la economía real al mismo punto inicial. ${ }^{1}$ El emperador se encontraba entonces ante la misma disyuntiva y volvía al mismo enfoque la segunda, cuarta o décima vez. Pero con una diferencia radical: en cada nuevo proceso, la primera fase - mayor actividad económica — era más corta y la segunda —inflaciónmás sostenida y fuerte. Y en cada etapa se intentaba siempre evitar los ajustes reales necesarios ante todas las distorsiones generadas por esta política de excesos monetarios.

\section{EL CASO DE JAPÓN}

Un caso interesante de discusión es el japonés. A inicios de los 9o, estalló la burbuja inmobiliaria de la bolsa de valores y de otros precios, y desde entonces se han dado los mismos debates antes mencionados, partiendo de un hecho básico: el producto interno bruto (PIB) nominal se ha mantenido esencialmente estancado desde hace 25 años - aunque cabe señalar que, teniendo en cuenta el envejecimiento y disminución de la población, los resultados en productividad real no son malos-. 
Por un lado, está la posición que defiende la expansión de la demanda vía fiscal y/o monetaria. De cierta manera, eso es lo que ya ha sucedido con resultados mediocres. The Economist (2015) y el Fondo Monetario Internacional (2016) aportan datos importantes: uno, la deuda bruta del gobierno se ha multiplicado en 4 veces desde 1990 de manera regular; dos, los activos del banco central aumentaron al 20\% del PIB hasta inicios de 2010, pero en los últimos años han sufrido una explosión hasta el 90\% del PIB —obviamente los dos indicadores están ligados porque el banco central monetiza la deuda pública- - Y los debates se dan alrededor de este último punto: cómo reactivar el crecimiento y evitar la deflación. Por ejemplo, en reciente artículo Joseph Stiglitz apunta en esa misma dirección:

Para empezar, un impuesto importante sobre el carbono, si está acompañado por «finanzas
verdes», estimularía una enorme inversión para modernizar la economía [...]. En ese caso,
el dinero generado por el impuesto podría utilizarse para reducir la deuda gubernamental;
de lo contrario, se podría usar para financiar inversiones en tecnología y educación [...].
Alternativamente, el gobierno podría cambiar la deuda por dinero que no reporte interés - la
monetización de deuda del gobierno, tan temida durante mucho tiempo- [...]. Si después de
todo esto todavía existiera evidencia de una falta de demanda, el gobierno podría reducir sus
impuestos al consumo, aumentar los créditos fiscales por inversiones, expandir los programas
de ayuda a los hogares de ingresos bajos y medios o invertir más en tecnología y educación, fi-
nanciando todo esto con emisión de moneda. (Stiglitz, 2016)

En concreto: a través de impuestos y gasto, el gobierno orienta la actividad económica, y lo puede financiar vía monetización de la deuda. Otras posiciones van a lo contrario: el problema del Japón tiene que ver con los fuertes cambios demográficos - la población ya empezó a disminuir - y con la baja productividad de ciertas actividades muy cerradas a la competencia, sobre todo los servicios. Stiglitz lo reconoce pero minimizándolo frente al resto.

[...] Los datos sobre la producción por hora trabajada sugieren un problema de lado de la oferta, que se manifiesta más claramente en el sector de los servicios, donde por lo general no se percibe el ingenio sorprendente que se ve en tantas industrias manufactureras. (Stiglitz, 2016)

Y lo que menos sentido tiene es utilizar instrumentos de monetización de la deuda estatal, o similares. La justificación para estas intervenciones monetarias ha sido la deflación en que ha caído la economía japonesa; pero ahí hay dos temas importantes que recordar: uno, la deflación tiene que ver con el estallido de la burbuja y las distorsiones muy importantes que persisten en precios absolutos y relativos - ajustes que no se dan porque la propio política de expansión monetaria está orientada a no permitirlo-; y dos: el ajuste en el sistema bancario ha sido también dilatado y retrasado por esos enfoques monetarios. ${ }^{2}$

\section{EL CASO EUROPEO}

Es similar: cómo estimular una economía que está alrededor de tasas negativas de crecimiento -recesión-y de precios - deflación-. Y ha prevalecido la posición del estímulo monetario/ fiscal, más aún cuando hace pocos años se reemplazó al presidente alemán del Banco Central Europeo por Mario Draghi, italiano - y, por tanto, con una cultura de creación monetaria que 
le venía desde la época del imperio romano, como antes señalé-. Los mismos datos permiten ver cómo los activos del banco central han pasado de menos del 10\% del PIB europeo al 30\% y creciendo; mientras que The Wall Street Journal (2015) señala que la inflación tiende a negativo y las autoridades monetarias corren hacia el estímulo monetario artificial, incluso habiendo ya pasado hacia la zona de tasas de interés negativas. De cierta manera, el caso americano es similar y muchos creen que es la política monetaria activa la que ha permitido cierta recuperación de la economía - mejor que en Europa en todo caso-, mientras otros insisten en que son factores reales intrínsecos de la economía que lo han permitido: flexibilidad laboral, movilidad, creatividad empresarial, etc. Para explicar el tema, voy a utilizar un escrito de Juan Ramón Rallo (2015) que es contrario a los paquetes artificiales de estímulo monetario, pero que explica con claridad lo que algunos creen son los pros y otros los contras.

El Banco Central Europeo acaba de anunciar una «flexibilización cuantitativa» (Quantitative Easing) por importe de 1,1 billones de euros [...]. Al entender de muchos, esta «inyección de dinero» en la economía es la clave de nuestra recuperación [...].

¿En qué consiste exactamente? El Quantitative Easing no es más que la compra de ciertos activos bancarios por parte del Banco Central [...] quien compra la deuda pública (u otra deuda privada) en manos de los bancos privados. ¿Y cómo la compra? Imprimiendo nuevos billetes de euro expresamente para ello (en realidad, incrementa el saldo de la cuenta corriente que los bancos tienen en el bce, pero el efecto es exactamente el mismo que imprimir nuevos billetes) [...]. ¿Qué efectos supuestamente tiene? Según se nos dice, los Quantitative Easing poseen varios efectos que redundan en beneficio del conjunto de la economía y que permitirían reanimarla. Para empezar, contribuyen a reducir los tipos de interés [...]. Segundo, la situación financiera de los bancos privados mejora: sus inversiones ya no están tan «atascadas» o «comprometidas» en créditos a largo plazo [...]. Tercero, la combinación de menores tipos de interés y del manguerazo de liquidez a los bancos debería incrementar la concesión de nuevos créditos a la economía productiva [...]. Además, dado que habrá un torrente de bancos deseosos de prestar a familias y empresas, los tipos de interés del crédito privado caerán, con lo que más gente querrá endeudarse. Cuarto, el aumento del crédito al sector privado permitirá incrementar el consumo y la inversión con base a la deuda. Mayor gasto privado tenderá a reavivar la economía y, de este modo, no sólo a reanimar la «actividad» sino también a elevar los precios, ahuyentando así el terrible fantasma de la deflación. Quinto, parte de ese gasto a crédito se filtrará hacia el exterior y $[\ldots]$ el euro se depreciará $[\ldots]$. Y sexto [...] estas condiciones de laxitud y bonanza se mantendrán tanto tiempo como sea necesario para relanzar el crecimiento económico constituirán un marco macroeconómico en el que los agentes se sentirán cómodos para volver a endeudarse, a invertir, a consumir y a contratar a más trabajadores. Todo un éxito. ¿Cuáles son sus contraindicaciones? Como debería resultar evidente, si los Quantitative Easings fueran tan maravillosos, no habría gobierno alguno en el mundo (ni siquiera los más sádicos con su población) que dejarán de aprovecharse de ellos [...], aunque el Quantitative Easing no vaya a provocar a medio plazo nada parecido a una elevada inflación, eso no significa que no pueda tener otras consecuencias perjudiciales.

El primer efecto es que el banco central pierde margen de maniobra a la hora de gestionar su moneda [...], la estrategia de entrada en el Quantitative Easing está muy clara; la estrategia de salida está de momento en pañales [...].

El segundo efecto es que los bajos tipos de interés no tienen por qué estimular un nuevo ciclo 
de endeudamiento que relance la economía, salvo acaso entre las administraciones públicas. Estas últimas sí siguen plenamente interesadas en mantener unos déficits públicos desbocados cuyo coste trasladan impunemente a las generaciones futuras [...]. Distinto es el caso de familias y empresas: si éstas siguen altamente endeudadas con respecto a su capacidad futura de generar riqueza, facilitarles de forma artificial el endeudamiento no las llevará normalmente a redoblar sus pasivos, por lo que el efectivo inyectado por el banco central a la banca privada permanecerá en las cajas fuertes de esta última [...], esto no significa que la reducción de tipos de interés del Quantitative Easing carezca de efectos adicionales [...], la reducción de tipos de interés de la flexibilización cuantitativa consolidará un contexto económico de alto endeudamiento y de activos sobrevalorados: lejos de facilitar el reajuste económico consistente en minorar nuestra deuda y en asignar el capital hacia los proyectos verdaderamente más valiosos- lo dificultará.

En tercer lugar, si los menores tipos de interés de la flexibilización cuantitativa sí estimularen una mayor concesión de nuevo crédito [...] habría más deuda y más riesgo. Por ende, mucha mayor fragilidad financiera: justo la receta que nos condujo al desastre de la crisis actual y por lo cual muchos de los que ahora defienden las flexibilizaciones cuantitativas se han cansado de exigir una mayor regulación del sistema financiero [...]. Por tanto, no sólo se financian proyectos empresariales más inseguros, sino que se concede una artificial ventaja competitiva a los proyectos más inseguros frente a los más seguros.

Y, por último, tampoco la depreciación del tipo de cambio, especialmente con la magnitud que está adoptando la del euro, tiene por qué ser positiva. Desde hace años el mundo está sumergido en una silenciosa guerra monetaria (China contra EE. UU., EE. UU. contra Europa, Japón contra EE. UU. y China, Europa contra todos...) que en algún momento nos ha perjudicado a todos [...] El problema de este tipo de depreciaciones es que impiden la construcción de una división internacional del trabajo verdaderamente duradera: la especialización de cada región del planeta no se determina por su ventaja competitiva estructural frente al resto, sino por la transitoria manipulación monetaria que se imprima [...]. (Rallo, 2015)

Y como los resultados de esta enorme inyección monetaria no han sido todo lo esperado, entonces incluso se quiere ir más lejos, como se ve en la siguiente nota de prensa (Badía y Monzón, 2016):

El BCE ha puesto en marcha una batería de medidas sin precedentes para apuntalar la inflación, por ahora, sin éxito [...]. Sin embargo, la firma noruega, Nordea, da un paso más allá y propone dar 1.300 euros a cada uno de los ciudadanos que viven en la eurozona. La región consta de 340 millones de habitantes, con lo que supondría inyectar 442.00o millones de euros, mucho menos de lo que va a inocular en el sistema a través del Quantitive Easing. Se trataría de poner en marcha lo que en los círculos financieros se conoce como helicopter money. El economista, estadístico e intelectual estadounidense, Milton Friedman, utilizó esa metáfora para tratar de entender lo que pasaría si el gobierno transfiriera dinero en efectivo a los ciudadanos (probablemente a través de pagos electrónicos, no mediante helicópteros) para reactivar la demanda en la economía [...]. El BCE, por ahora, ha descartado esta idea. «Helicopter Money no forma parte actualmente de la discusión del Consejo de Gobierno (BCE)», señaló [...] Benoit Coeure, miembro del comité ejecutivo banco central [...], pero insiste Nordea: «Estamos en un entorno en el que los bancos centrales tienen que intentar algo nuevo». 
[...] Christopher Dembik, economista de Saxo Bank, se preguntaba «¿Por qué no distribuir el dinero directamente a los hogares, dado que el dinero no funciona a través de los ban$\cos$ ? [...], facilitar a todos los hogares de la zona euro una cantidad específica, que se abonaría en una cuenta bancaria especial y sólo podría ser utilizada para el pago de la deuda existente», lo que, en su opinión, repercutiría en una mayor confianza en las perspectivas económicas y, a su vez, en un aumento del poder adquisitivo, que estimularía el consumo. «Para aquellos que no tienen deudas, podríamos suponer que el dinero pagado sería invertido, por ejemplo, en proyectos de infraestructura europeas, que estimulen el crecimiento y permitan un rendimiento a largo plazo», añadía [...]. (Badía y Monzón, 2016)

Y en la misma dirección va la propuesta de dinero electrónico de Barrdear et al. (2016):

Como una situación de base, consideramos una situación en la cual un stock inicial de CBDC (dinero electrónico del banco central) igual al 30\% del PIB se emite contra un monto igual de deuda estatal [...]. Nuestras simulaciones sugieren que esta política tiene varios beneficios. Primero, lleva a un aumento del nivel steady-state del PIB en $3 \%$, debido a una reducción en la tasa de interés real, en impuestos distorsionantes y costos de transacciones monetarias. Segundo, puede contribuir a la estabilización del ciclo de la economía, al disponerse de un segundo instrumento de política que controla ya sea la cantidad o el precio de los CBDC de manera contracíclica [...] en el lado negativo, hay que considerar los costos y riesgos asociados a la transición a un mecanismos monetario y financiero diferente. (Barrdear et al., 2016, p. 3 [traducción propia])

Vemos, pues, cómo en el mundo, incluso en sociedades donde los bancos centrales son independientes y actúan de manera «responsable», se ha avanzado en la dirección de un discurso muy claro: la creación adicional y excesiva de dinero por los bancos centrales - bajo diversos formatos- es necesaria para reactivar la economía. Esto va en contra de ciertos principios básicos de la economía real. Los tres roles del dinero - medio de pago, depósito de valor, unidad de cuenta - son muy importantes, pero que todos están condicionados y «están por detrás» de la actividad económica real. El dinero es el medio de pago para intercambios reales. Es la unidad de cuenta para transacciones reales. Y es el depósito de valor de una actividad real como es el ahorro. El dinero solo facilita procesos reales, pero no los crea. La actividad real puede existir sin el dinero - a través del trueque aunque sea ineficiente-, pero no lo contrario. Pero ése es el pecado monetario del mundo desde hace cientos o miles de años, y que especialmente luego del fin del patrón oro y el abandono de los acuerdos de Bretton Woods (1944-1971), ahora se ha reactivado: intentar reemplazar actividades y decisiones reales, con creación monetaria en exceso donde, más temprano que tarde, se aplica directamente la ecuación cuantitativa del dinero: todo el exceso de dinero va a inflación y devaluación, y nada a crecimiento económico - todo lo contrario, el crecimiento decae-.

Esto lo hemos visto en el mundo estos años. La inflación no es necesariamente en bienes al consumidor, sino en activos financiados con excesiva creación monetaria y bajas tasas de interés, por ejemplo, bolsa de valores, inmobiliario o bienes como el petróleo. Y esas burbujas estallan inevitablemente porque siempre se vuelve a la realidad: la riqueza es proporcional a la productividad no a la cantidad de dinero que se inyecta, a la deuda no sustentada en ahorro 
o las artificiales bajas tasas de interés. Y si todo eso sucede en el mundo, con más razón en un país de baja disciplina e institucionalidad como el Ecuador.

\section{EL CAMINO MONETARIO EN ECUADOR}

Ecuador también tiene una extraña historia monetaria. Cuando muchos de los países del continente caen en procesos hiperinflacionarios entre los años 70 y 9o, el país, junto con Colombia y Paraguay, es el único que lo evita a pesar de crecientes tasas de inflación - de un 12\% en los 70 se alcanza puntualmente casi el 100\% hacia 1998-1999- salvo en los años 1994-1996 en que la inflación vuelve hacia el 20-25\% anual. Naturalmente, esa historia monetaria, aunque no incluye procesos hiperinflacionarios, sí es historia de un deterioro monetario continuo (ver Figuras 1 y 2). No es de sorprenderse que el promedio de inflación y devaluación sea muy similar, alrededor del 16\% anual — siendo las dos variables solo caras diferentes de una misma medalla-, y que esto sin duda en períodos de varias décadas constituye un factor distorsionador de la actividad económica muy importante.

Sin embargo, cuando la mayor parte — sino todos- los países, desde la segunda mitad de los 90, ya se habían alejado de esos desequilibrios, el Ecuador es casi el único que se encuentra al borde de la hiperinflación en la crisis de 1998-1999, devaluación del 400\% en un año y del $100 \%$ en las últimas semanas de 1999, que en poco tiempo hubiera llevado a un enorme ajuste hacia arriba de la inflación interna. Y en ese momento el Ecuador toma la decisión que, casi, ningún otro ha tomado en circunstancias similares, al salir de la crisis de desconfianza monetaria cambiando su patrón monetario.

Efectivamente, en los países que han entrado en crisis hiperinflacionarias, lo que normalmente ha sucedido es que no ha existido la capacidad de llegar a acuerdos colectivos que permitan frenar las causas de este fenómeno - básicamente desequilibrios fiscales y externos que se trasladan a mayor y creciente creación monetaria, ciertamente a través de complejos procesos políticos y sociales-, y es solo cuando ya se ha caído en el pozo hiperinflacionario que la sociedad ha emprendido al mismo tiempo en medidas de corto plazo - nueva moneda con recorte de algunos ceros, nuevo tipo de cambio- y de largo plazo - nueva institucionalidad monetaria y fiscal más independiente y ortodoxa-. El Ecuador no esperó pasar por ese tránsito tan socialmente destructivo, sino que adoptó en enero del 2000 el dólar para frenar el enorme deterioro monetario y, por tanto, social. En lugar de reformas institucionales internas, optó por tomar una institucionalidad monetaria externa: el dólar.

Tema de análisis sociológico muy interesante: ¿Por qué el país evitó los riesgos hiperinflacionarios durante mucho tiempo? ¿Por qué, ante la enorme crisis del 98-99, optó por la dolarización? Quizás hay explicaciones muy simples, como la búsqueda del gobierno de Jamil Mahuad de un escape con la dolarización, a la grave situación social y política, pero quizás hay trasfondos sociológicos más importantes que no son objeto de este análisis pero quedan ahí flotando. En definitiva el Ecuador ha sido doblemente inusual. En épocas «normales» fue de los muy pocos que nunca llevó tan lejos sus desequilibrios como para entrar en hiperinflación, pero cuando estuvo al borde de la misma fue el único que escogió el camino de la dolarización como salida. 


\section{EL CAMINO A LA DOLARIZACIÓN EN ECUADOR}

En 1998-200o, cayeron sobre la economía varias «plagas de Egipto» - la verdadera tormenta perfecta-: guerra con el Perú de 1995, crisis internacional de 1997, derrumbe del precio del petróleo a USD 7 el barril - por debajo de los costos de producción, lo que equivale a USD 15 de hoy-, fenómeno El Niño de alta intensidad, a lo cual hay que sumar problemas estructurales de la economía como la mala calidad de la política que impide tomar decisiones sensatas en momentos difíciles, y un sistema bancario muy fragilizado por la guerra de 1995, además de créditos vinculados que venían de 20 años atrás, pero que en el momento de la crisis generan un grave compromiso en las decisiones estratégicas de los grupos empresariales dueños de bancos y de otras empresas financiadas por sus bancos. ¿Salvar al banco o a las demás empresas? Y generalmente - desgraciadamente - se orientan hacia lo segundo - lo cual es ética, social y económicamente inaceptable - porque los bancos son normalmente «salvados» por los gobiernos. ${ }^{3}$

Por razones económicas y políticas, la decisión del gobierno fue finalmente de crear dinero masivamente para resolver a la vez los problemas bancarios, estatales y de actividad económica real. De ahí el resultado inevitable: cada vez menos actividad económica, pero mayor inflación y devaluación, esto último de manera más rápida e inmediata porque los agentes económicos - sobre todos de clase media baja hacia arriba - pierden confianza aceleradamente en la moneda local y trasladan sus tenencias monetarias a dólares, mientras la inflación normalmente sigue con rezago a la devaluación — hasta que los dos se disparan en mano a mano-.

$\mathrm{Y}$ en ese entorno de enorme desconfianza se da un continuo proceso de pérdida de recursos por parte del sistema bancario, por varias frentes: el efecto de menos liquidez en el conjunto de la economía lo cual afectaba a la banca igual o más que el resto de agentes, retiro directos de depósitos de los clientes y una enorme dificultad para recuperar créditos —en algunos casos por las dificultades propias de los deudores, en otros casos ante la eventualidad de una intervención del Estado en esos bancos y la posibilidad «de no pagarle al Estado» como tantas veces ha sucedido en el pasado con diversas condonaciones legales en la banca estatal-.

Este proceso dura 18 meses desde mediados de 1998, y el gobierno intenta diversos mecanismos: i) Tipo de cambio. Se arranca con un sistema fijo en 5000 sucres por dólar, pero para marzo de 1999 ya se habían gastado ingentes recursos de la reserva monetaria internacional, por lo que se decide pasar a un sistema de libre flotación dentro del cual hay muy rápidamente una devaluación del 100\%, esto solo se frena y revierte con el congelamiento de depósitos —otra decisión ética, social y económicamente inaceptable-. Unos meses más tarde, el banco central interviene en el mercado con tasas de interés muy elevadas - por encima del $100 \%$ anual para operaciones de pocos días-. Cuando el tipo de cambio igual se devalúa en el 100\% en las últimas semanas del 1999... viene la dolarización. ii) Banca. Inicialmente quiebran bancos pequeños, muchos de los cuales habían sido financieras ya quebradas a las que por una extraña consecuencia de la presión de los grupos de interés, se les había permitido convertirse en bancos con varias ventajas entre las cuales consta la capitalización diferida - y, obviamente, son estos bancos que incrementan las tasas de interés y el riesgo del conjunto del sistema-. Luego quiebra el Filanbanco, uno de los dos bancos más grandes del país y se crea la Agencia de Garantía de Depósitos (AGD) como mecanismo de doble propósito: por un lado, 
Figura 1. Inflación en Ecuador desde 1940

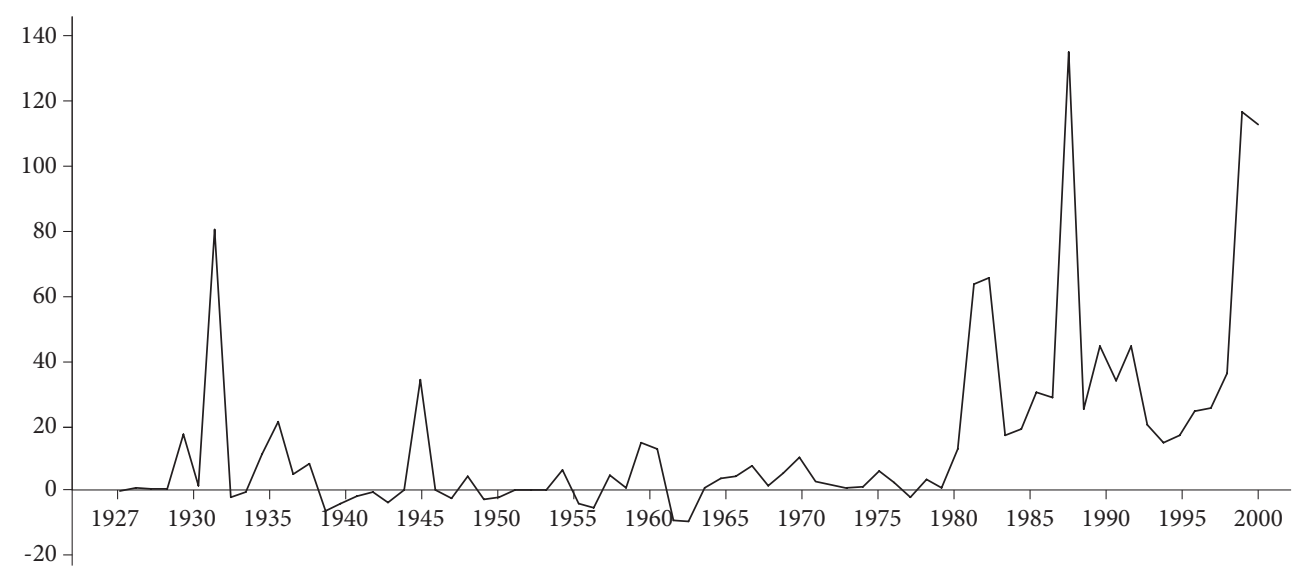

Fuente: Paredes P. L. (2016)

Figura 2. Variación anual del tipo de cambio sucre/dólar

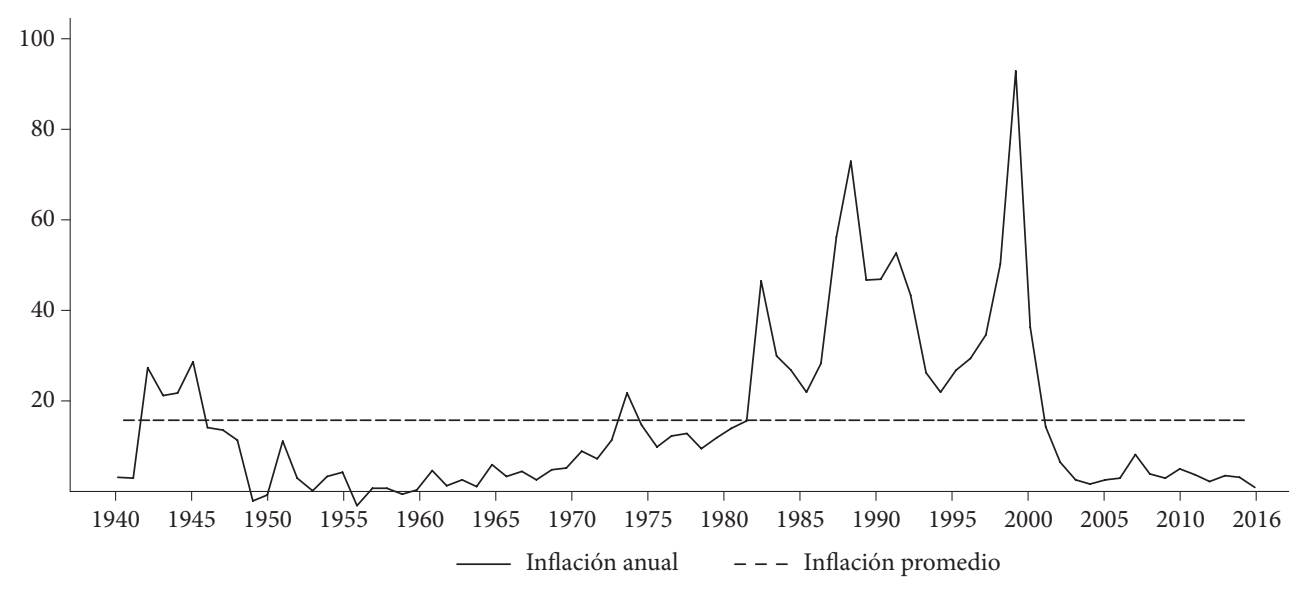

Fuente: Paredes P. L. (2016)

el absurdo intento de evitar el pánico bancario con un seguro universal que no era posible financiar de manera real — solo vía creación monetaria, lo que aumentaba la inestabilidad del sistema macroeconómico-; y, por otro lado, como resultado nuevamente de grupos de interés intentando salvar sus fondos. Más tarde, está al borde de la caída el otro grande, el Banco del Progreso, y su potencial efecto de contagio lleva al gobierno primero al feriado bancario y luego al congelamiento de los depósitos. Error tras error, y abuso inaceptable de los derechos básicos de la gente. iii) Fiscal. Se intenta combinar reducción del gasto e incremento de ingresos, entre los cuales se reemplaza el impuesto a la renta por una tasa sobre las transacciones 
financieras. Desgraciadamente, el efecto es una mayor desintermediación financiera. También se discute la posibilidad de pagar o no la deuda externa, lo primero para mantener relaciones sanas con el sistema financiero internacional, lo segundo para ahorrar recursos ante la profundidad de la crisis.

Todo esto se mantuvo combinado hasta enero de 2000, cuando surgen básicamente tres propuestas: i) implementar una regla más estricta de creación monetaria por parte del banco central, como lo sugería el Foro Alternativo. Esto generaba al menos dos problemas. Uno, cómo plantear una regla creíble que permitiera devolver al menos parcialmente la confianza en la moneda local, al mismo tiempo que llevar a la economía por un sendero de equilibro que frenara la alta inflación y la creciente recesión: no es fácil compaginar una regla monetaria estricta con el lento descenso de las expectativas de los agentes económicos, generalmente los bancos centrales son los perdedores al abandonar la regla ante los resultados iniciales insuficientes. Dos, de cierta manera, el banco central ya tenía esas reglas y habían sido violadas, por lo cual había muchas dudas de que esto pudiera implementarse y tener éxito; ii) ir a un sistema de convertibilidad, que es parecido al anterior, pero con una regla más estricta: solo se puede crear moneda local en la medida que hay respaldo de dólares en el banco central en base a una tasa de conversión fija. Las dudas eran las mismas que en el caso (i) anterior, y más aún, teniendo en cuenta el insuficiente flujo de dólares hacia la economía, por lo cual el paso por una fuerte recesión era casi inevitable y, probablemente, eso hubiera llevado al abandono del sistema de convertibilidad; iii) polarizar la economía, es decir, que ya no haya un intermediario monetario como el banco central, sino que los dólares entren y salgan de la economía solo pasando por las manos y decisiones directas de los agentes económicos. La dolarización no es una regla más estricta, es un sistema diferente.

$\mathrm{Al}$ adoptar esta última alternativa, se rompió completamente con la desconfianza monetaria y muy rápidamente se frenó el descalabro monetario y real. Sin embargo, el ajuste inflacionario duró un par de años, porque era necesario que se reajusten los precios relativos por la diferencia que se había dado en el último año y medio entre la inflación interna del 100\% y la devaluación del 400\%. Ese es uno de los temas que más sorprendió en el proceso, pero no debió haber sorprendido tanto. Yo mismo señalaba esta necesidad de ajuste apenas iniciado este nuevo proceso (Paredes, 2000). En cambio, el ajuste positivo en el crecimiento real fue muy rápido (ver Figura 3). Pero la implementación de la dolarización tenía como visión algo más amplia que solo un cambio en el mecanismo cambiario y monetario. Era algo similar a lo que se describe en De la Torre et al. (2003) para la convertibilidad en Argentina:

Desde su introducción en abril de 1991, la convertibilidad fue más que un simple mecanismo cambiario para bajar la inflación [...], estaba destinada a producir una ruptura irreversible de la inestabilidad monetaria y financiera. Se esperaba que deje su marca en la psicología argentina un punto de no retorno y sea un camino de una sola vía [...]

Además, [...] se convertiría en un eje institucional que ayudaría a poner orden en otras instituciones y alinear los incentivos de los agentes no solo en la esfera económica (proceso fiscal, regulación bancaria, mercados laborales, etc.), sino también en el social y político. La convertibilidad, de hecho, se convirtió en un componente central del contrato social, una institución clave en la vida política y económica del país. La convertibilidad no fue un contrato 
como cualquier otro; era más bien un núcleo o contrato principal, del que otros contratos (financieros y no financieros) dependían. (De la Torre et al., 2003, pp. 3-4 [traducción propia])

Quizás no se lo ha expresado de esa manera en el caso ecuatoriano, pero la dolarización ciertamente tenía esas intenciones y atributos; aunque no todos —o quizás pocos, desgraciadamente- se hayan alcanzado por la enorme resistencia de la sociedad ecuatoriana a mejorar su institucionalidad. Pero esa resistencia, incluso dentro del marco de la dolarización, es la que justifica mantener el sistema en el Ecuador, cualquier otra alternativa solo ahondaría los problemas de estabilidad, institucionalidad y manipulación del dinero a favor de ciertos grupos - empezando por el propio gobierno-. La dolarización es de los pocos acuerdos colectivos en el Ecuador.

\section{ELEMENTOS DEL DEBATE Y POR QUÉ EL GOBIERNO}

SE QUEJA SIN MUCHO SENTIDO DE LA DOLARIZACIÓN

Inicialmente, hay al menos dos preguntas importantes que plantearse, ambas ligadas: i) ¿De qué sirve una devaluación?; y ii) ¿Qué es la zona monetaria óptima?

En el primer caso, es «muy sencillo» dicen algunos: cuando un país tiene un shock externo - baja del precio de sus exportaciones, por ejemplo - es legítimo devaluar su moneda para intentar recuperar "competitividad de precios», lo cual se da de dos maneras: i) expresados en moneda extranjera, todos los precios y salarios internos caen, lo cual permite al sector exportador ser más rentable; y ii) se trasladan recursos del conjunto de la economía hacia el sector exportador —incluyendo al gobierno- - Otros dirán, no sirve la devaluación y más bien es solo una transferencia oculta de recursos hacia el gobierno y exportadores y, por eso, es mejor tener un sistema como la dolarización o, mejor aún, el patrón oro, en el que simplemente todas las monedas se valoran en relación a algo externo - oro-, con lo cual se mantiene el valor intrínseco del dinero - como se comentó- y no hay variaciones de valor de las monedas entre países. Claro, hay que dar respuesta a la duda: ¿Y qué pasa entonces cuando un país sufre un shock externo como se mencionó? Respuesta: vía ajustes de precios y salarios en los sectores que los requieren específicamente, no hay necesidad de hacer un ajuste de todos los precios y salarios de la economía como lo hace la devaluación. En realidad, no devaluar es lo más sensato, porque en el fondo es como al interior de un país, ciertamente hay diferencias entre provincias, unas son más ricas, más productivas, hay más o menos problemas en unas u otras como catástrofes naturales o problemas en la venta de sus productos, los salarios no son iguales y los precios de ciertas cosas tampoco - los llamados «no transables» que son los bienes y servicios que no se negocian entre provincias como, por ejemplo, un corte de pelo, un terreno o un almuerzo local, estas cosas no valen lo mismo en Quito que en Pujilí o Bucay-. Sin embargo, nadie plantea que cuando hay problemas específicos en una provincia, tenga una moneda propia que se devalúe para ayudar a resolver sus problemas. Pero...

En cuanto a la segunda pregunta, obviamente el tema del ajuste en una provincia que tiene problemas, esconde una particularidad que no debemos olvidar: en gran medida no se necesita la devaluación entre provincias porque las personas de la provincia afectada puede migrar a las demás provincias para encontrar empleo y porque el conjunto del país normalmente hace un esfuerzo, vía gobierno, para ayudar a sacar adelante a la afectada. Éste es el argumento 
de la «zona monetaria óptima»: un país puede tomar la moneda de otro país y, por tanto, no utilizar la devaluación como instrumento de ajuste —igual que sucede entre las provinciascuando se cumplen razonablemente cuatro condiciones: i) los dos países tienen intercambios comerciales y de inversión muy importantes; ii) los dos países navegan en direcciones más o menos similares, con ciclos económicos similares; iii) existe la posibilidad de migración de personas de uno a otro en caso de problemas; y iv) existe apoyo fiscal o monetario hacia el más afectado. ${ }^{4}$ Por esta razón —una de las razones, porque la más importante realmente es disponer de financiamiento inflacionario y devaluatorio para el gobierno- es que la Revolución Ciudadana se opone a la dolarización, no se cumplen realmente las condiciones señaladas para haber adoptado el dólar. Uno, el Ecuador tiene - dejando de lado el petróleo- solo un tercio o 40\% de sus intercambios con Estados Unidos. Dos, no navegamos en la misma dirección: como ahora sucede, el valor del dólar en el mundo puede moverse en una dirección totalmente contraria a lo que el Ecuador necesita. Tres, no hay fácil migración hacia los Estados Unidos, todo lo contrario. Cuatro, no hay apoyo ni fiscal ni monetario de los Estados Unidos hacia el Ecuador en caso de problemas.

Y ¿qué se responde del otro lado para defender la dolarización? Sencillo, si entendemos en qué consisten los pros y contras de la dolarización, debemos manejar esto últimos con sabiduría y en ese caso los argumentos de la «zona monetaria óptima» se tornan secundarios, porque las virtudes de la dolarización se potencian. Esa prudencia significa: i) no excederse en épocas de supuesta bonanza, sobre todo mantener al tamaño del Estado bajo control porque genera actividad económica, mas no productividad; ii) mantener precios y sobre todo salarios en línea con la productividad y no con el espejismo de la actividad económica; iii) flexibilidad laboral para crecer en las épocas buenas y ajustarse en las malas; iv) bajar deuda en épocas de bonanza; y v) tener fondos de ahorro que permitan a las épocas de vacas gordas fondear a las de vacas flacas.

Está claro que el actual gobierno ha hecho exactamente lo contrario de todo esto, por ende cuando nos dice: «Siempre dije que la dolarización era muy mala para el Ecuador, si hoy tuviéramos la posibilidad de devaluar resolveríamos nuestros problemas»; lo que en realidad debería decir es: «Como hice todo lo necesario para afectar a la dolarización, ahora necesitaría que la abandonemos para poder devaluar».

\section{LOS PROS Y LOS CONTRAS}

Por supuesto que la dolarización, como toda decisión o mecanismo económico, tiene sus pros y contras. Lo importante es decidir cuál de los dos pesa más. En el caso ecuatoriano todo este debate se puede resumir en lo siguiente.

Los pros esenciales de la dolarización han sido, para citar tres primeros: i) La estabilidad. La tasa de inflación se ha mantenido, por primera vez desde hace 40 años, de manera sostenida por debajo del $5 \%$ anual y hubiera sido incluso menor a no ser por las presiones que el exceso de gasto público ha generado en la demanda agregada. La estabilidad en dolarización es la baja inflación más factores adicionales: la posibilidad de planificar en el largo plazo, el hecho de que todos los contratos — sobre todo laborales y financieros - están en la misma moneda sin que exista riesgo de descalce entre unos y otros, etc. ii) La equidad. Es un enorme 
Figura 3. Crecimiento PIB trimestral (antes y después de la dolarización)

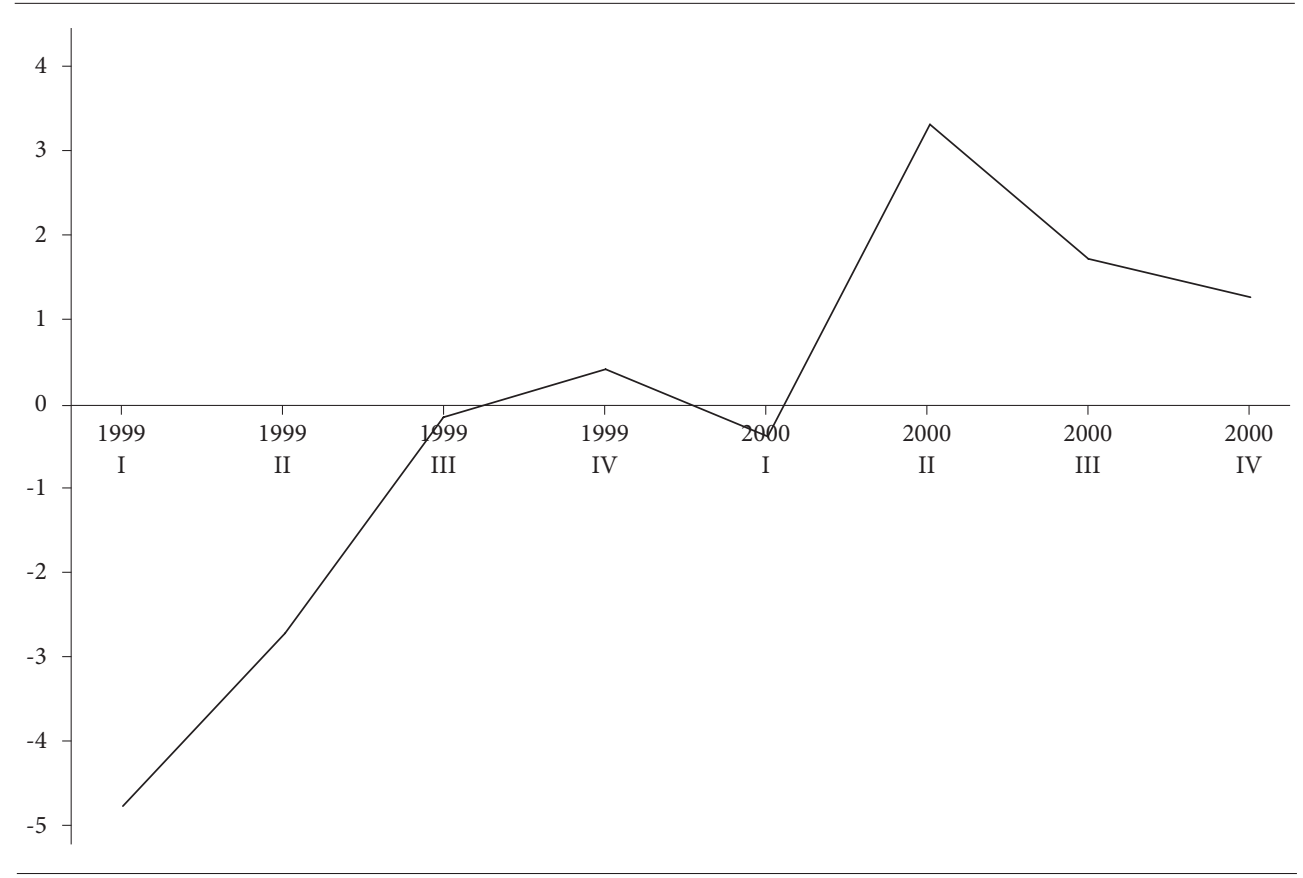

Fuente: Boletín de Cuentas Nacionales trimestrales, Banco Central del Ecuador, n. ${ }^{\circ}$ 6o, marzo de 2007

cambio el que todos los grupos sociales estén cubiertos por el mismo paraguas monetario lo cual no significa que los pobres dejen de serlo solo por razones monetarias-. Uno de los mayores males sociales de las economías con moneda propia es que los pobres están cubiertos por un paraguas monetario de muy mala calidad, mientras los grupos de mayores recursos se cubren con un paraguas en moneda extranjera, que no solo les protege, sino que en muchos casos les genera ganancias relativas adicionales. iii) La productividad. No hay duda de que en épocas de inestabilidad las empresas dedican más recursos de lo necesario a la protección financiera y, de cierta manera más grave aún, a generar ganancias en la especulación financiera que, con frecuencia, son mayores a las ganancias en el negocio real. En lugar del gerente de producción, el gerente financiero es el rey de la empresa. En dolarización este incentivo desaparece, porque las tasas de interés —incluso cuando son más altas de lo razonable - son relativamente estables y no hay tipo de cambio contra el que apostar -el tipo de cambio entre el dólar y terceras monedas es un factor relativamente secundario-. Como la especulación financiera es un factor de suma cero, es evidente que las ganancias que realizan las empresas medianas y grandes es en detrimento de las empresas pequeñas y de los individuos. En dolarización el enfoque es hacia la productividad. Esto se nota de manera muy clara en la microeconomía del Ecuador desde el 2000, pero su efecto macroeconómico no es tan marcado si medimos simplemente el PIB dividido por las horas trabajadas- porque el fuerte aumento 
del precio del petróleo que se da desde el 2005, ha llevado a un aumento enorme del Estado ecuatoriano - sobre todo desde 2008- lo cual ha tenido un efecto negativo sobre la productividad promedio.

Pero se pueden apreciar también otras dos ventajas son: iv) El riesgo moral en la banca. Al actuar los bancos centrales como prestamistas de última instancia, la banca - sobre todo mediana y grande - tiene una protección casi automática que casi ningún otro sector tiene en la sociedad: el Estado está dispuesto a intervenir para «salvarlos» cuando sea necesario «en pro del bien común». Ésta es sin duda una de las causas de las continuas crisis financieras en el mundo desde hace 500 años: creación monetaria excesiva por parte de los bancos centrales y/o multiplicación excesiva del dinero por parte del sistema bancario. Los excesos se dan por el riesgo moral: los políticos y los banqueros siempre pueden trasladar sus malas decisiones a los demás. La dolarización rompe esto porque ya no hay prestamista de última instancia, la banca debe crear sus propios fondos para protegerse en caso de problemas y asumir sus propios riegos. v) El dinero como factor de libertad. Para Rueff, en materia monetaria -igual que en el ámbito bancario-, no es cuestión de innovar por innovar, «una moneda convertible es una moneda intercambiable, a igualdad de valor, libremente y sin control de ninguna naturaleza, contra toda otra moneda convertible. Los profanos creen que esto es una simple disposición de técnica financiera. En realidad es una cuestión de civilización, ya que está ligado al estatuto de la persona humana. Es la indispensable condición de la libertad económica (Rueff, 1971). Esto último lo refuerza, Gabriela Calderón (2015):

[...] En los distintos ámbitos de la sociedad ecuatoriana rige un Estado de legalidad, mas no un imperio de la Ley o Estado de Derecho. El poder de nuestra clase política se encuentra prácticamente ilimitado y la Constitución y la legislación son meros reflejos de ese poder en lugar de ser sus límites.

Pero hay una brillante excepción: el imperio de la Ley en la dolarización, [...] nuestra clase política perdió hace 15 años el poder de manipular el valor del dinero en que los ecuatorianos cobramos, ahorramos y realizamos transacciones [...]. Todos los ecuatorianos, sin excepción, obtuvieron soberanía individual sobre su dinero y se puso fin a un apartheid entre quienes podían obtener un tipo de cambio favorable y el resto de la población. Atrás quedaron los días en que solo los ricos podían colocar sus ahorros en una moneda que no fuese manipulada por nuestra clase política.

[...] El economista Steve Hanke de Johns Hopkins University explica que: «Si el gobierno retiene la opción de devaluar, aquellos que poseen dinero emitido por el gobierno se enfrentan a la posibilidad de que sus derechos de propiedad sean confiscados de una manera arbitraria [...] mediante devaluaciones. De tal manera que los gobiernos que fracasan en proteger el valor del dinero son culpables de no respetar el Estado de Derecho. (Calderón, 2015, pp. 1-2)

Por otro lado, los contras también son muy claros y se resumen en dos aspectos: i) ya no hay la posibilidad de crear dinero de manera exógena para estimular la economía cuando ésta entra en un ciclo negativo; y ii) no hay la posibilidad de devaluar el tipo de cambio para mejorar los precios relativos frente al exterior y ganar competitividad vía precios - lo que permite temporalmente sostener exportaciones y frenar importaciones-. 
En un entorno de alta indisciplina como el Ecuador, los pros ciertamente son mucho mayores que los contras. De eso debemos estar claros y no dudar. El propio gobierno, que constantemente ataca a la dolarización, debería estar consciente de lo mucho que le ha servido este mecanismo: en la época buena del petróleo le evitó un tipo de cambio apreciado - como sucedió en Colombia o Perú- y entrada de capitales solo especulativos de corto plazo y en la época mala que la devaluación y la desconfianza se lleven capitales masivos al exterior, y con ellos un proceso inflacionario difícil de detener. Hubiéramos caído sin duda en la tentación de devaluaciones fiscales, atractivas para que el Estado se siga financiando vía impuestos inflacionarios y devaluatorios - ya que el Estado es un exportador neto de divisas-. Estos pros y contras se evalúan también a continuación, junto con esa idea tan repetida por el gobierno de que «si tuviéramos la posibilidad de devaluar se resolverían los problemas». Lawrence White menciona:

La dolarización ha sido un éxito evidente. [...] Incluso el presidente Rafael Correa, quien se ha quejado de que la dolarización es una "camisa de fuerza» porque evita poder manejar la política monetaria — esto es, de hecho, su mayor virtud-, se compromete a no deshacerla.

[...] ¿Cómo una depreciación de la moneda podría proporcionar una «válvula de alivio» en un período de disminución de los ingresos por exportaciones de petróleo? El socorro no puede provenir de cambiar los precios mundiales de exportaciones importantes de Ecuador. Igual que el precio del petróleo se establece competitiva y flexiblemente en los mercados mundiales, también sucede para las flores, frutas frescas y mariscos. Las flores cultivadas en un país con moneda débil no tienen una ventaja sobre los precios de venta de las flores cultivadas en un país de moneda fuerte. El argumento coherente para justificar una depreciación «competitiva» es que considerados en términos de dólares hay un recorte de los salarios e insumos que tienen un precio en moneda local; [...] las empresas de productores no petroleros, pueden tomar ventaja de mayores márgenes de beneficio para expandir su producción y sus ventas. [...] Existen dos regímenes alternativos a la dolarización a considerar: un tipo de cambio ligado con flexibilidad al dólar y un tipo de cambio flotante. El primer problema con una fijación ajustable es que ningún experto sabe en tiempo real exactamente cuánto los salarios y los precios de insumos deben cortarse en términos de dólar y, por lo tanto, el banco central no puede saber exactamente cuánto devaluar la moneda frente al dólar. Puede fácilmente errar en el sentido de exagerar. El segundo, y más grave problema, es que este tipo de régimen simplemente no es viable en un mundo de libre circulación de capitales. Cuando el mercado empieza a sospechar que una devaluación está amenazando, los especuladores atacan la moneda, vaciando las reservas en dólares del banco central, y forzando a una devaluación que es probable sea mayor de lo que era teóricamente deseada.

Un régimen cambiario de flotación libre, evita el problema del ataque especulativo. Y el mercado, más que el banco central local, ajusta el tipo de cambio. Pero flotar tiene su propio problema fundamental: se elimina la restricción, que la dolarización sí ofrece, contra el problema crónico de la excesiva creación de dinero por parte del banco central. El «miedo a flotar» demostrado históricamente por muchos países latinoamericanos está justificado: la flotación torna impredecibles la tasa de inflación y la tasa de cambio, lo cual daña a los mercados locales de capitales y la financiación de inversiones productivas [...]. El reemplazo del dólar por un nuevo sucre sería inmediatamente recibido con sospechas justificadas de que, como con el antiguo sucre, el nuevo será copiosamente emitido. Pocos se cambiarían voluntariamente de dólares al nuevo Sucre. 
[...] La sugerencia de que la dolarización está dañando al Ecuador, se basa en una muy miope contabilidad de costos y beneficios. (White, 2015)

Está claro que el tema de fondo de la dolarización — más que en cualquier otro sistema, y más aún en un entorno como el del Ecuador, de dependencia de un commodity de precios muy variables como el petróleo- es que, al ser un sistema monetario inflexible, lo que se haga de bueno o malo durante las buenas épocas, va a ser esencial para determinar su viabilidad en las malas épocas. El dilema esencial es que generalmente - al menos ha sido el caso del Ecuadoren las buenas épocas no se generan estas disciplinas fiscales y laborales porque no es necesario y se quiere empujar al máximo la dinámica económica porque esto genera réditos políticos, y cuando vienen los malos momentos ya no se lo puede hacer porque es muy tarde y siempre hay la justificación «no es el momento». Por lo tanto, los desequilibrios se crean y se profundizan en los buenos y en los malos ciclos de la economía. Y los excesos han sido importantes y claros en el caso ecuatoriano, en el período 2007-2014 - ya antes de los shocks externos-: i) El salario mínimo, con lo adicionales legales pero sin la seguridad social, es actualmente de USD 450 mensuales, es decir, casi USD 3 la hora, o un 40\% del PIB horario por trabajador; ciertamente, bastante alto dado el nivel de productividad promedio de la economía y el hecho que el PIB probablemente está sobrevalorado en relación al nuevo tipo de cambio real de equilibrio —eso ya lo estamos viendo: el PIB está disminuyendo por volumen y por precio-. ii) Los salarios del sector público son 30 a $40 \%$ superiores a los privados para tareas que posiblemente son formalmente iguales, pero no lo son en términos de productividad. iii) Las reglas laborales en el sector privado son cada vez más estrictas, complejas, costosas e inflexibles. iv) El gasto público ha crecido desde 2007 para llegar al 44\% del PIB en 2014, y aunque la descomposición se ha ido sesgando hacia la inversión -14 puntos del total — en general, tanto el gasto corriente -incluyendo importantes subsidios- como el de inversión, son altamente ineficientes. iv) No se implementó en el ciclo anterior, ninguno de los mecanismos posibles que generan un colchón financiero para el cambio del ciclo. Las reservas internacionales eran de apenas USD 4000 millones $-4 \%$ del PIB - , de los cuales más de la mitad eran reservas bancarias - y probablemente la mitad de esas reservas están comprometidas en préstamos a instituciones públicas, es decir, de liquidez casi nula-. No había la contratación de ninguna línea de crédito contingente o seguro petrolero. Quizás el único recurso adicional eran los USD 2500 millones $-2,5 \%$ del PIB - del fondo de liquidez de la banca — fondo para precautelar colectivamente cualquier corrida bancaria-. Por tanto, el endeudamiento masivo surge como alternativa.

Aquí cabe anotar que es necesario precisar dos aspectos sobre los cuales se han dado malas interpretaciones respecto con la dolarización —ambos aspectos vinculados entre sí-: i) Hay la creencia de que la dolarización ha funcionado «gracias» al aumento del precio del petróleo, así como el ingreso de remesas de los migrantes y otros flujos externos, y, por tanto, por esos dólares adicionales que ha aportado a la economía. Error. La dolarización puede funcionar con cualquier cantidad de dólares, y crecerá más o menos no en función de dicha cantidad, sino de las decisiones de ahorro, inversión y productividad que se tomen. Lo que sí es problemático en un sistema rígido como la dolarización, son las variaciones bruscas en los flujos, por ejemplo, pasar de un alto nivel de ingresos externos al que la economía se ha acostumbrado, 
a un nivel más bajo al que debe acostumbrarse. Los ajustes nominales y reales necesarios para pasar de un nivel a otro, son complejos. Y eso es lo que ha sucedido en el Ecuador, nos acostumbramos a vivir a un nivel muy alto del precio del petróleo - alrededor de USD 100 por barril—; y la transición al nuevo nivel —alrededor de 40 dólares - es difícil. ii) La otra creencia: como la dolarización es un sistema basado en el flujo de dólares, hay que evitar que las divisas salgan vía mecanismos que limitan las importaciones. Error. En dolarización, el ajuste de oferta y demanda monetaria es automático y, por tanto, no se necesitan mecanismos externos que lo regulen. Lo que sí es cierto es que el ajuste será menos real y sostenible, cuanto más se mantenga alto el gasto público y más nos endeudemos para mantenerlo - reemplazar los ingresos petroleros con deuda-. Lo único que hacen las restricciones externas como aranceles o salvaguardias, es preservar el alto nivel de gasto público y trasladar el ajuste al sector privado vía importaciones.

\section{LOS RIESGOS CUANDO NO SE HA HECHO LO NECESARIO}

Los errores cometidos en las buenas épocas, no son fáciles de corregir en las malas. La experiencia muestra que el ajuste fiscal siempre es lento e insuficiente, como señala De la Torre et al.:

Para empezar, flexibilidad nominal en el gasto fiscal raramente se verifica en la práctica [...]. Las realidades políticas de los procesos democráticos limitan severamente el margen para reducir el gasto fiscal nominal, especialmente en el contexto de una recesión. Como se ha señalado, este fue un factor determinante en la evolución de la trampa Argentina. Ajuste nominal del presupuesto argentino se ha logrado sólo en una medida limitada y en el contexto de una prolongada recesión. En efecto, la reducción en el gasto público que debería haber acompañado a la limitación del acceso al financiamiento externo, no ha ido más allá de una insuficiente y políticamente costosa reducción salarial que nunca pretende ser permanente (De la Torre et al., 2003, p. 15 [traducción propia]).

Y entonces surge la tentación de mecanismos creativos para resolver los problemas latentes, y lo que más preocupa son al menos dos aspectos en el caso ecuatoriano: i) Que se tomen los fondos que respaldan la liquidez del sistema financiero, ya sean las reservas bancarias en el banco central - una parte ya ha sido probablemente tomada con inversiones en papeles públicos - o el fondo de liquidez. En cualquier caso, contagiar al sistema financiero de la crisis es extremadamente riesgoso como la experiencia de tantos países lo ha mostrado. ii) Que se emita cuasidinero, apuntando las preocupaciones hacia el dinero electrónico que fue aprobado en el marco de una nueva Ley de Régimen Monetario en agosto del 2014, que en el caso ecuatoriano tiene una importante particularidad: es el único - o uno de los pocos países en el mundo- donde es el propio banco central, es decir, el gobierno, dada su absoluta dependencia legal, el único autorizado a emitirlo y controlarlo - los demás son solo agentes operativos- Hay el temor de que el gobierno pague compromisos fiscales de baja denominación - salarios o bonos - a través de dinero electrónico cargado a los teléfonos inteligentes de los respectivos agentes. Ahí podrían suceder tres cosas si se alcanza un monto importante: a) que este dinero electrónico se negocie con descuento en los mercados, lo cual implicaría un proceso de inflación y devaluación interna por exceso de creación monetaria (Espinosa Goded, 
2016); b) que los agentes trasladen a los bancos este dinero electrónico y que éstos no tengan ninguna alternativa para manejar estos activos de menor valor - el banco central obviamente no lo recibiría-; c) que se genere una enorme incertidumbre en la economía que se traslade a retiro de depósitos en la banca.

Las tres cosas son directamente contrarias a un sistema de dolarización, y en caso de montos importantes, socavarán lentamente el sistema — es difícil compartir la confianza de algunos analistas que creen se puede emitir cuasidinero, distinto del dólar, sin socavar el sistema-. Este riesgo de contagiar de problemas al sistema financiero lo señala claramente De la Torre et al.:

Al cerrarse los mercados de capitales, la restricción impuesta por la convertibilidad fue violada por un poco de colocación obligatoria de deuda interna. Y cuando incluso el obligatorio acceso a bancos locales y otras fuentes locales de financiación (como los fondos de pensiones) estaba agotado, el sector público ha recurrido a la emisión de los gobiernos centrales y provinciales lo que difería de papel moneda solo estéticamente.

[...] Se pueden extraer dos lecciones [...]: en primer lugar, hay peligros en el intento de imponer una fuerte restricción presupuestaria, cuando el gobierno es incapaz de cuadrar sus cuentas fiscales en el corto plazo. Un riesgo grave es la propagación de los problemas fiscales en el sistema financiero [...]; en segundo lugar, la disciplina monetaria de los sistemas monetarios rígidos parece más fácil de abandonar de lo que se cree a menudo. Esto queda ilustrado por la relativa facilidad con la que el gobierno argentino recurrió a imprimir dinero con otro nombre (patacones, y similares). También está claro que lo mismo podría haber ocurrido en dolarización que no habría superado la trampa mientras el desequilibrio fiscal fuera determinante (al menos en el corto plazo) y no fuera fácilmente reversible mediante una reducción en el gasto público nominal. La dolarización también habría estado probablemente acompañada por una proliferación de cuasi-monedas locales que habrían reflejado el simple hecho de que un déficit fiscal no puede ser eliminado simplemente por un sistema monetario. El cuasi-dinero más que un problema en sí mismo es, por tanto, un síntoma de una profunda contradicción entre un estricto marco monetario y las rigideces nominales que este marco no puede eliminar por arte de magia. (De la Torre et al., 2003, pp. 15-16)

Y ese cuasidinero paralelo ya está empezando a circular en Ecuador, con los atrasos a los contratistas que se pagan con bonos y, más aún, con los papeles del banco central que sirven para cancelar obligaciones tributarias y se negocian en bolsa. Las autoridades estatales, siempre aquí y allá, lo han justificado con el argumento de que nada de eso sirve para aumentar la creación monetaria, pero en realidad sí lo es porque en el fondo la pregunta más importante es: ¿Ese dinero tiene como trasfondo - respaldo- una operación — ahorro- real? Y la respuesta es, obviamente, no. La preocupación existe sin duda, pero el principal freno a la salida de la dolarización parece ser lo difícil del proceso y la enorme inestabilidad que generaría todos los ajustes ante shocks externos son complejos, en dolarización aún más; pero incluir la desdolarización en el paquete parece ser muy costoso-. Pero el riesgo existe porque contrariamente a lo que se desearía, la dolarización no ha permitido en el Ecuador ahondar reformas estructurales hacia la disciplina y productividad que el país requiere, más bien quién sabe si la estabilidad generada por la dolarización no ha sido un factor que en sí mismo ha frenado las reformas - si sabemos que tenemos un colchón de seguridad, nos preocupamos 
menos del trasfondo real-. Pero si la propia dolarización no ha logrado frenar nuestra indisciplina, con más razón debemos mantenerla.

\section{CONCLUSIÓN}

En realidad, en el Ecuador, en lugar de siquiera pensar en abandonar la dolarización, debemos más bien fortalecerla, o fortalecer la libertad y seguridad monetaria, como, por ejemplo, señala Gabriela Calderón (2015):

La dolarización ha cumplido su propósito de proveerle a los ecuatorianos una moneda sana: es un medio de cambio universal, un depósito de valor y una unidad de medida. Y eso no es poca cosa $[\ldots]$.

Para fortalecer la dolarización se requieren una serie de reformas que expandan el Estado de Derecho más allá del ámbito monetario [...]. 1. Eliminar el Banco Central del Ecuador. 2. Libertad para elegir la mejor moneda. 3. Integración financiera [...]. La integración financiera, junto con la territorialidad tributaria, generaría principalmente cuatro beneficios para los ecuatorianos: (1) tasas de interés cercanas a los niveles internacionales, que suelen ser más bajas que las que han prevalecido en nuestro mercado; (2) un mayor acceso al crédito y a créditos de mayor volumen; (3) un sistema financiero estable gracias a la presencia de bancos internacionales, que fungen como prestamistas de última instancia en casos de escasez de liquidez; y, (4) aumentaría la bancarización del país, entendiendo este índice como el volumen total del crédito concedido como porcentaje del PIB. (Calderón, 2015, pp. 6-7)

¿Hay la tentación de salir de la dolarización? Sin duda, sí, ya que la economía — sociedadsigue siendo profundamente inestable. ¿Deberíamos abandonarla? Sin ninguna duda, no, porque para una sociedad indisciplinada, la dolarización, con sus pros y contras, es el mejor sistema posible porque evita muchas tentaciones que solo nos llevan a círculos viciosos muy peligrosos en lugar de enfocarnos en los temas esenciales del desarrollo como son productividad, estabilidad y equidad. En realidad, como algunos han señalado, no se debe ni siquiera elevar la dolarización a principio constitucional, sino algo que fomente la mayor libertad de escoger la moneda, como por ejemplo: «No podrá haber en la República medio de pago de curso forzoso. En consecuencia, cualquier individuo puede rechazar todo billete u otra cédula que no le inspire confianza, ya sea de origen oficial o particular». Lo que el Ecuador necesita no es abandonar la dolarización, sino más bien todo lo contrario: fortalecer la libertad monetaria que, en nuestro entorno institucional, es casi imposible de lograr con una moneda propia.

\section{NOTAS}

1 Semejante resultado ya fue explicado, en su momento, por M. Friedman al hablar del papel neutral del dinero (Friedman, 1968).

2 Vale aquí recordar que hay dos tipos de deflaciones. Una, es el resultado del estallido de burbujas generadas por los excesos monetarios, cuando en realidad son ajustes de precios relativos que se convierten en deflación cuando las autoridades monetarias intentan evitarlos. Dos, la deflación por productividad, donde la caída de precios es el mecanismo normal para generar riqueza, porque permite aumentar salarios reales sin ajustes en salarios nominales - que luego se tornan rígidos y complican el 
entorno-; y al mismo tiempo favorece al ahorrista en relación al deudor lo que es —o debería ser- el círculo natural de la economía.

3 De hecho, hasta se podría plantear que la situación vivida por la economía ecuatoriana en la segunda mitad de los 9o, entra en la categoría de las llamadas «crisis gemelas»: combinación de una crisis financiera con una crisis monetaria, expresada esta última normalmente como una crisis de tipo de cambio (Kaminsky y Reinhart, 1999).

4 Entre los primeros pensadores en proponer el concepto de «zona monetaria óptima» y reflexionar sobre las condiciones necesarias para su existencia, se encuentra Robert Mundell. Para Mundell, tales «zonas óptimas» quedan definidas en aquellas regiones que en su interior poseen una elevada movilidad de factores que les permite ajustarse ante shocks, y que externamente se enfrentan a otras regiones ante las cuales poseen una baja movilidad de factores que impide un ajuste de shocks y requiere la existencia de tipos de cambio flexibles. Debido a su movilidad interna de factores, tales regiones serían las más adecuadas en poseer una misma moneda (Mundell, 1961).

\section{REFERENCIAS}

Banco Central del Ecuador (2007). Cuentas Nacionales Trimestrales, (60), (s. p.).

Barrdear, J. and Kumhof, M. (2016). The Macroeconomics of Central Bank issuing digital currencies. Staff Working Paper n. ${ }^{\circ}$ 605. Bank of England. Recuperado de http://www.bankofengland.co.uk/ research/Documents/workingpapers /2016/swp605.pdf

Calderón, G. (2015). Dolarización y libertad: El caso ecuatoriano. El Cato. Recuperado de https://www. elcato.org/ sites/default/files/ens-2015-09-09.pdf

De la Torre, A., Levy Yeyati, E., and Schmukler, S. (2003). Living and Dying with Hard Pegs: The Rise and Fall of Argentina's Currency Board. Documento de trabajo 03/2003. Universidad Torcuato di Tella. Recuperado de http:// www.utdt.edu/Upload/CIF_wp/wpcif-032003.pdf

Espinosa Goded, L. (2016). El dinero electrónico ecuatoriano: historia de un engendro monetario. Revista Koyuntura USFQ, (62), 1-4.

Friedman, M. (1968). The Role of Monetary Policy. The American Economic Review, 58(1), 1-17.

Fondo Monetario Internacional (2016). Perspectivas de la economía mundial. Demanda reprimida: Sintomas y remedios. Recuperado de https://www.imf.org/external/spanish/pubs/ft/weo/2016/o2/ pdf/texts.pdf

Kaminsky G. and Reinhart, C. (1999). The Twin Crises: The Causes of Banking and Balance-Of-Payments Problems. The American Economic Review, 89(3), 473-500.

Levy, E. and Sturzenegger, F. (2003). Dollarization: A Primer. Massachusetts, usA: The Miт Press.

Mundell, R. (1961). A Theory of Optimum Currency Areas. The American Economic Review, 51(4), 657-665.

Paredes, P. L. (200o). El libro de la dolarización. Quito, Ecuador: Megagraph.

Paredes, P. L. (2016). 80 años (y algo más) de historia monetaria. Quito, Ecuador: CIP.

Rallo, J. R. (2015). ¿Qué es y qué efectos tiene un Quantitative Easing? juanramonrallo.com. Recuperado de http:// juanramonrallo.com/2015/o1/que-es-y-que-efectos-tiene-un-quantitative-easing/

Rueff, J. (1971). Le Peché Monétaire d'Occident. Paris, France: Plon.

Stiglitz, J. (2016). Un plan económico mejor para Japón. Project Syndicate. Recuperado de https://www.project-syndicate.org/commentary/new-economic-plan-for-japan-by-joseph-e--stiglitz-2016-o9?ve rsion=spanish\&barrier=true

The Economist (2015). The Japanese solution. Recuperado de http://www.economist.com/news/financeand-econo mics/21677648-despite-shinzo-abes-best-efforts-japans-economic-future-will-be-leap 
The Wall Street Journal (2015). Divergence Paths for u. s., European Central Banks. Recuperado de http:// www.wsj.com/articles/divergent-paths-for-u-s-european-central-banks-1448830021

White, L. (2015). Dollarization is hurting Ecuador? Don't Believe It. CaTo. Recuperado de https://www. cato.org/blog/dollarization-hurting-ecuador-dont-believe-it 
